\title{
AVALIAÇÃO VISUAL DA INFLUÊNCIA DA APLICAÇÃO DE CIPROCONAZOL+TIAMETOXAM NO CRESCIMENTO DE MUDAS DE COFFEA CANEPHORA
}

\author{
MARTINS, Lima Deleon ${ }^{1}$ \\ RODRIGUES, Wagner Nunes ${ }^{2}$ \\ TOMAZ, Marcelo Antonio ${ }^{3}$
}

\begin{abstract}
RESUMO: Existem poucos trabalhos que ilustram a fitotoxidez causada por fungicidas sistêmicos, em plantas jovens de café, sendo uma informação faltante para esta cadeia produtiva. Assim, desta forma objetivou-se, com este trabalho, avaliar visualmente a influência da aplicação, via solo, de tiametoxam-ciproconazol, de ação fungicidainseticida, no crescimento de mudas de clones de café conilon que compõem a cultivar clonal 'Vitória Incaper 8142', sob condições de casa de vegetação. Utilisou-se delineamento inteiramente casualizado, com distribuição fatorial de 13x2, com quatro repetições, sendo os fatores: 13 clones que compõem a cultivar 'Incaper 8142'; e ausência e presença da aplicação de granulado de solo tiametoxam-ciproconazol. Nas condições avaliadas, todos os clones apresentaram visualmente desenvolvimento inferior na presença da aplicação, via solo, de tiametoxamciproconazol.
\end{abstract}

Palavras-chave: Controle químico. Hemileia vastatrix Berk. et Br.. Efeito tônico.

SUMMARY: There are few works that illustrate the phytotoxicity caused by fungicides in young coffee plants, being this a missing information for this productive chain. Therefore, this work aimed to visually evaluate the influence of the application of thiamethoxam-cyproconazole, through soil, in the growth of seedlings of the clones that compose the clonal cultivar 'Vitória Incaper 8142' of conilon coffee, under greenhouse conditions. The statistic design utilized was in completely randomized design with factorial distribution of $13 \times 2$, with four replications, being the factors: 13 clones that compose the clonal cultivar 'Vitória Incaper 8142', and the presence and absence of application of cyproconazole-thiamethoxam. In the studied conditions, all clones were visually less developed in the presence of application of thiamethoxam-cyproconazole.

Keywords: Chemical control. Hemileia vastatrix Berk. et Br.. Tonic effect.

\section{INTRODUÇÃO}

Os atuais modelos tecnológicos de produção de café exigem ações pontuais que permitam obter uma melhoria constante na qualidade do produto. Com base nesta afirmativa, as pesquisas têm demonstrado que a condução adequada da lavoura cafeeira é primordial para a obtenção de bebidas de qualidade (ABRAHÃO et al., 2009). Neste contexto, de manejo da lavoura cafeeira, um fator de extrema importância é a ocorrência de doenças foliares, que pode causar redução da produção e, secundariamente, depreciação da qualidade do grão (CHAVES; ZAMBOLIM, 1985).

\footnotetext{
${ }^{1}$ M. Sc., Doutorando em Produção Vegetal - CCA/UFES - Centro de Ciências Agrárias da Universidade Federal do Espírito Santo, Alto Universitário, Cx.P. 16, CEP: 29500-000, Alegre-ES. E-mail: deleon_lima@ hotmail.com

${ }^{2}$ M. Sc., Doutorando em Produção Vegetal - CCA/UFES - Centro de Ciências Agrárias da Universidade Federal do Espírito Santo, Alto Universitário, Cx. P. 16, CEP: 29500-000, Alegre-ES. E-mail: wagnernunes86@ hotmail.com

${ }^{3}$ D. Sc., Professor - CCA/UFES - Centro de Ciências Agrárias da Universidade Federal do Espírito Santo, Alto Universitário, Cx. P. 16, CEP: 29500-000, Alegre-ES. E-mail: (CCA/UFES), Alegre-ES. E-mail: tomaz@cca.ufes.br
} 
-*A ferrugem, causada pelo fungo Hemileia vastatrix Berk. et Br., é considerada a principal doença do cafeeiro, devido a vários fatores relacionados ao patogêno e a avaria causada a produção da

-*A ferrugem, causada pelo fungo Hemileia vastatrix Berk. et Br., é considerada a principal doença do cafeeiro, devido a vários fatores relacionados ao patogêno e a avaria causada a produção da cultura. $\mathrm{O}$ fungo causa lesões nas folhas, reduz a área fotossinteticamente ativa da planta, provoca desfolha e comprometendo a produtividade do cafeeiro (ZAMBOLIM et al., 2002).

Dentro de varias formas de controle, pode ser feito o controle químico, através de fungicidas aplicados via foliar ou via solo. A aplicação via solo de produtos sistêmicos de ação fungicida é uma alternativa para manejar a ferrugem em lavouras de café que possuem características adversas, como cultivos em locais excessivamente íngremes, plantações extensivas e plantios adensados (SILVA-ACUNÃ et al., 1993).

Além do efeito fungicida, os produtos sistêmicos de solo podem gerar um efeito fisiológico no desenvolvimento das plantas, caracterizado por aumento no enfolhamento, melhoria no vigor da planta e alteração no tom de verde das folhas. Esse efeito é chamado de efeito tônico (CARVALHO et al. 1997).

O efeito tônico é considerado benéfico, aumentando a resistência da planta e diminuindo a possibilidade de infecções. Entretanto, o mesmo pode causar um colapso metabólico em plantas jovens, dentro outros mecanismos, por intermédio de fitotoxidez. Existem poucos trabalhos que ilustram a fitotoxidez causada por fungicidas sistêmicos, em plantas jovens de café.

Desta forma objetivou-se, com este trabalho, avaliar visualmente a influência da aplicação, via solo, de tiametoxam-ciproconazol, de ação fungicida-inseticida, no crescimento de mudas de clones de café conilon que compõem a cultivar clonal 'Vitória Incaper 8142', sob condições de casa de vegetação.

\section{METODOLOGIA}

O experimento foi conduzido em casa de vegetação na área experimental do Centro de Ciências Agrárias da Universidade Federal do Espírito Santo (CCA-UFES), em Alegre-ES.

As mudas dos 13 clones que compõem a cultivar 'Vitória Incaper 8142' foram obtidas junto ao Instituto Capixaba de Pesquisa Agropecuária (Incaper), todas com dois pares de folhas. Estas foram cultivadas em vasos plásticos com capacidade de $10 \mathrm{dm}^{3}$. O solo utilizado no enchimento dos vasos foi coletado na área experimental do CCA-UFES, sendo que posteriormente uma amostra deste solo foi encaminhada ao laboratório para análise química e fisica (Tabela 1).

Tabela 1 - Atributos físicos e químicos dos solos estudados.

(Continua)

$\begin{array}{lr}\text { Atributos } & \text { LVAarg } \\ \text { Areia Grossa }\left(\mathrm{g} \mathrm{kg}^{-1}\right)^{1} & 410 \\ \text { Areia Fina }\left(\mathrm{g} \mathrm{kg}^{-1}\right)^{1} & 73 \\ \text { Silte }\left(\mathrm{g} \mathrm{kg}^{-1}\right)^{1} & 91 \\ \text { Argila }\left(\mathrm{g} \mathrm{kg}^{-1}\right)^{1} & 426 \\ \text { Densidade do solo }\left(\mathrm{kg} \mathrm{dm}^{-3}\right)^{2} & 1,2 \\ \mathrm{pH}^{3} & 5,9 \\ \mathrm{P}\left(\mathrm{mg} \mathrm{dm}^{-3}\right)^{4} & 3,0 \\ \mathrm{~K}\left(\mathrm{mg} \mathrm{dm}^{-3}\right)^{5} & 125,0 \\ \mathrm{Ca}\left(\mathrm{cmolc} \mathrm{dm}^{-3}\right)^{6} & 2,1 \\ \mathrm{Mg}\left(\mathrm{cmolc} \mathrm{dm}^{-3}\right)^{6} & 0,9\end{array}$


Tabela 1 - Atributos físicos e químicos dos solos estudados.

(Conclusão)

$\mathrm{Al}\left(\mathrm{cmolc} \mathrm{dm}^{-3}\right)^{7}$

$\mathrm{H}+\mathrm{Al}\left(\mathrm{cmolc} \mathrm{dm}^{-3}\right)^{8}$

Matéria orgânica $\left(\mathrm{g} \mathrm{kg}^{-1}\right)^{9}$

Soma de Bases (cmolc $\mathrm{dm}^{-3}$ )

CTC potencial (cmolc $\mathrm{dm}^{-3}$ )

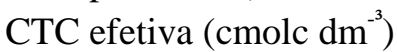

Saturação por bases (\%)

Saturação por alumínio (\%)
0,0

31,4

3,3

6,6

3,3

50,2

0,0

${ }^{1}$ Método da Pipeta (Agitação Lenta); ${ }^{2}$ Método da Proveta; ${ }^{3 .} \mathrm{pH}$ em água (relação 1:2,5); ${ }^{4}$ Extraído por Mehlich-1 e determinado por colorimetria; ${ }^{5}$ Extraído por Mehlich-1 e determinado por fotometria de chama; ${ }^{6 .}$ Extraído com cloreto de potássio $1 \mathrm{~mol} \mathrm{~L}-1$ e determinado por titulometria; ${ }^{7}$ Extraído com cloreto de potássio $1 \mathrm{~mol} \mathrm{L-1}$ e determinado por espectrofotômetro de absorção atômica; ${ }^{8}$ Extraído com acetato de cálcio 0,5 mol L-1, pH 7,0 e determinado por titulação; ${ }^{9}$ Extraído por oxidação, via úmida, com dicromato de potássio em meio sulfúrico e determinado por titulação (EMBRAPA, 1997).

A adubação com macro e micronutrientes foi realizada de acordo com a recomendação para estudos em ambiente controlado (NOVAIS et al., 1991). A adubação com fósforo foi aplicada em dose única, no plantio. A adubação com nitrogênio, potássio e micronutrientes foi realizada em quatro aplicações em cobertura, iniciando-se aos 30 dias após o plantio das mudas e as demais com intervalo de 30 dias entre aplicações.

O delineamento experimental utilizado foi inteiramente casualizado (DIC) com quatro repetições, seguindo o esquema fatorial $13 \times 2$, sendo os fatores: 13 clones que compõem a a cultivar 'Vitória Incaper 8142' (V1, V2, V3, V4, V5, V6, V7, V8, V9, V10, V11, V12 e V13); com e sem aplicação de ciproconazol+tiametoxam. A unidade experimental foi composta por um vaso contendo uma muda de café.

A aplicação dos ingredientes ativos ciproconazol+tiametoxan, foi feita por via solo utilizando o produto comercial (Verdadero ${ }^{\circledR} 600$ WG) na formulação granulado dispersível (WG). A dose recomendada pelo fabricante é de $1000 \mathrm{~g} \mathrm{ha}^{-1}$ do produto comercial, diluídos em 400 litros de água. Para adequar a recomendação do fabricante para uso em vaso, levou-se em consideração: número de plantas por hectare recomendado para a cultivar clonal 'Vitótia Incaper 8142' (2222 plantas ha $\left.{ }^{-1}\right)$, o volume de uma cova de café $\left(0,64 \mathrm{~m}^{3}\right)$ adotando $40 \times 40 \times 40 \mathrm{~cm}$, a dose recomendada do produto e a diluição feita em 400 litros de água. Desta forma obteve-se com os cálculos a dose de 0,070312 gramas do produto comercial vaso $^{-1}$ diluídos em $29 \mathrm{ml}$ de água. O produto que tem natureza granulada passou por uma leve maceração, a fim de facilitar a diluição e foi pesado em balança de precisão. A calda do produto foi aplicada, com o auxílio de uma seringa, a $10 \mathrm{~cm}$ das mudas em toda a superfície do solo contido no vaso, 20 dias após o transplantio.

A irrigação foi realizada mantendo-se a umidade do solo durante todo período do experimento a $60 \%$ do volume total de poros, e os tratos culturais foram realizados manualmente de acordo com a necessidade. O período de ação residual do produto ciproconazol+tiametoxam na planta varia entre 120 e 150 dias (SOUZA et al., 2009). Assim após 150 dias de cultivo, foi avaliado visualmente o desenvolvimento das plantas de café conilon em todos os tratamentos, para posterior descrição. 


\section{RESULTADOS E DISCUSSÃO}

A aplicação, via solo, do produto sistêmico tiametoxam-ciproconazo, de ação inseticidafungicida, visualmente, diminuiu o desenvolvimentos de todos os clones da cultivar 'Vitória Incaper 8142' (Figura 1).
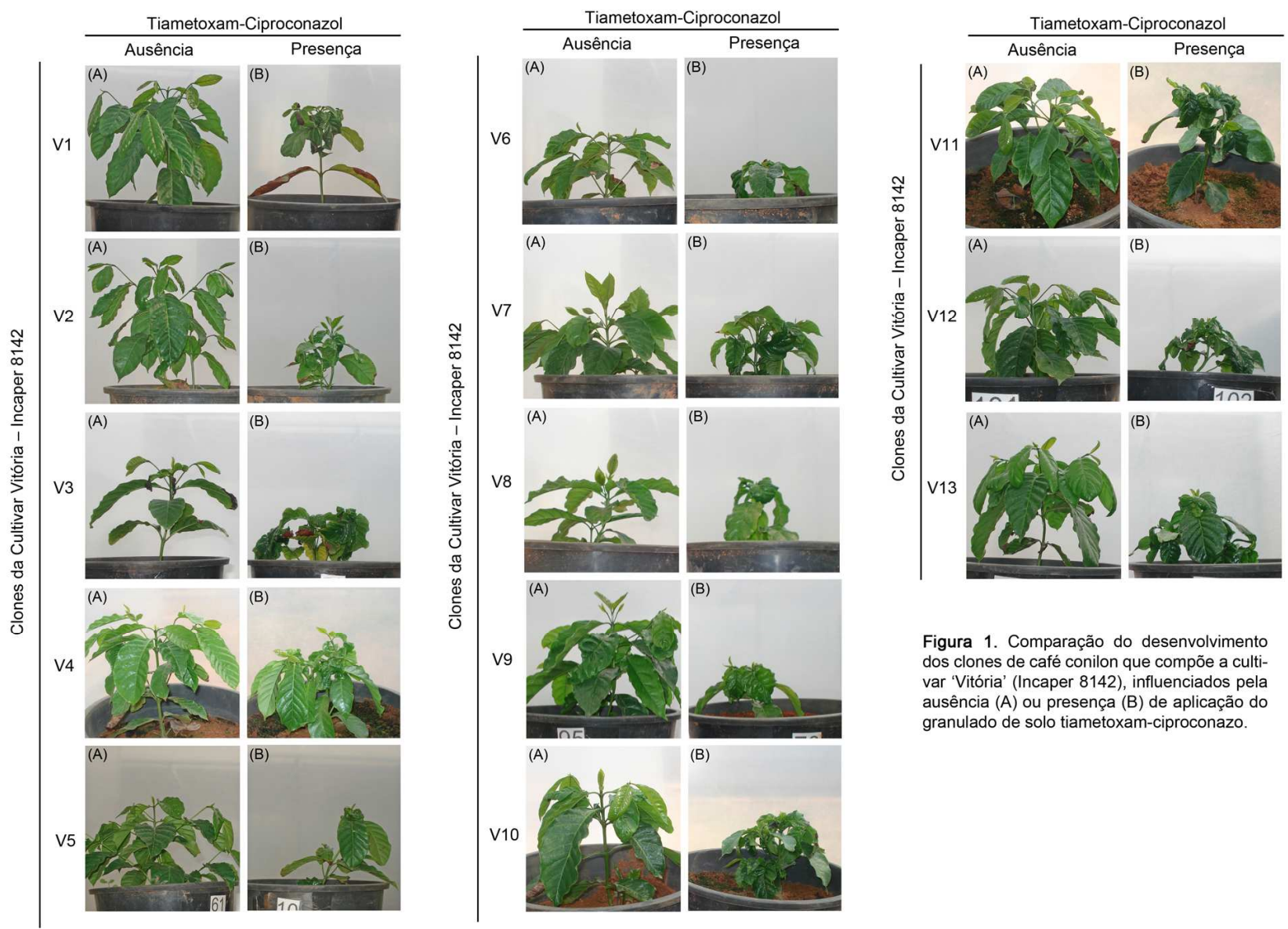

Figura 1. Comparação do desenvolvimento dos clones de café conilon que compõe a cultivar 'Vitória' (Incaper 8142), influenciados pela ausência $(A)$ ou presença $(B)$ de aplicação do granulado de solo tiametoxam-ciproconazo.

Estes resultados corroboram com Paradela et al. (2006), onde visualmente mudas de café arábica, na presença de fungicidas triazóis, de ação sistêmica administrados via solo, tiveram crescimento afetado pela ação hormonal de produtos sistêmicos, aplicados via solo.

Após o produto sistêmico, aplicado via solo, ser absorvido e translocado via xilema, processo este que acontece rapidamente, o princípio ativo instala-se nas folhas, aumentando a atividade fotossintética da mesma. Este fato deve-se a concentração hormonal que o mesmo possui (CARVALHO et al. 1997).

A atuação das moléculas dos princípios ativos que possuem a característica de ação hormonal, basicamente acontece de duas formas. A primeira seria aumentar o transporte iônico, incrementando a nutrição mineral da planta, por intermédio da ativação das proteínas de membranas celulares. A segunda seria relacionada ao aumento da atividade enzimática promovendo aumento do metabolismo primário e secundário, aumento da síntese de aminoácidos e da síntese de hormônios vegetais. Segundo Castro (2006) o aumento do vigor e produção das plantas (efeito tônico) estariam relacionados com as respostas as essas proteínas e a biossíntese hormonal.

Quando administrado em mudas no viveiro ou no campo, o efeito tônico do granulado de solo é depressivo, causando uma fitotoxidez nas plantas tratadas (PARADELA et al., 2006). A causa da 
fitotoxidez, possivelmente, possui como base o fato da carga hormonal acelerar o seu desenvolvimento, causando uma desordem fisiologica. Baseado nas afirmativas de Castro (2006) pressupõem que o excesso hormonal proporciona a ativação das proteínas da membrana celular, em escala excessiva, interferindo no transporte iônico, desbalanceado a nutrição mineral da planta.

Segundo Paradela et al. (2006) está desordem fisiológica causa sintomas variados, como, enrugamento, mancha foliar, redução de internódio, necrose de folhas, epinastia foliar, bronzeamento, nanismo e deficiências nutricionais variadas, no tecido foliar. Estes sintomas também foram encontrados neste estudo.

Estes resultados corroboram como o de Pupo de Moraes (1974), onde foi evidenciado que a aplicação do fungicida sistêmico de solo, do grupo dos triazóis, apresentou controle satisfatório da ferrugem, porém, as plantas que receberam a aplicação do fungicida apresentaram sintomas fitotóxicos, caracterizando menor crescimento das plantas de café.

Paradela et al. (2006), analisando visualmente mudas de café arábica, na presença de fungicidas triazóis, de ação sistêmica administrados via solo, verificaram que o crescimento das mudas de café foram afetados pela ação hormonal do granulado de solo.

\section{REFERÊNCIAS}

ABRAHÃO, A. A. et al. Influência de safras agrícolas e tratamentos fungicidas no café cereja descascado e bóia. Ciência e Agrotecnologia, Lavras, v. 33, n. especial, p. 1919-1925, 2009.

CARVALHO, G. R. et al. Efeito do triadimenol e benzilaminopurina no desenvolvimento de brotos in vitro do cafeeiro cv. catuaí. Revista Unimar, v. 19, n.3, p. 767-775, 1997.

CASTRO, P. R. C. Agroquímicos de controle hormonal na agricultura tropical. Piracicaba: ESALQ/Divisão de Biblioteca e Documentação, 2006. 46 p.

CHAVES, G.M.; ZAMBOLIM, L. Conceito de doenças em plantas. Informe Agropecuário, Belo Horizonte, v.2, n.122, p.6-7, 1985.

EMPRESA BRASILEIRA DE PESQUISA AGROPECUÁRIA — EMBRAPA. Manual de métodos de análises de solo. 2. ed. Rio de Janeiro: Ministério da Agricultura e do Abastecimento, 1997. 212p.

NOVAIS, R. F. et al. Ensaio em ambiente controlado. In: OLIVEIRA, A. J. et al. Métodos de pesquisa em fertilidade do solo. Brasília: EMBRAPA-SAE, 1991. p.189-254.

PARADELA, A. L et al. Avaliação do índice de fitotoxidez de triazóis em mudas de café e eficiência dos triazóis aplicados via foliar no controle da ferrugem (Hemileia vastatrix) do cafeeiro (coffea arabica).

Fitopatologia Brasileira. v.32, n.2, 2006.

PUPO DE MORAES, F. R. Absorção de fungicidas sistêmicos por via foliar e radicular no controle da ferrugem do cafeeiro (Hemilais vastatrix. Berk e Br). In: CONGRESSO BRASILEIRO SOBRE PESQUISAS CAFEEIRAS, 2., Anais... Poços de Caldas , 1974, p. 146-147.

SILVA-ACUNÃ, R. et al. Controle da ferrugem do cafeeiro com triadimenol via solo, na Venezuela. Fitopatologia Brasileira, v.18, n.1, p.70-75, 1993. 
SOUZA, A. F. et al. Manejo fitossanitário da ferrugem e do bicho-mineiro dentro dos princípios da produção integrada do café. In: ZAMBOLIM, L. Tecnologias para a produção do café conilon. Viçosa: Universidade Federal de Viçosa, 2009. p.47-64.

ZAMBOLIM, L. et al. Epidemiologia e controle integrado da ferrugem-do-cafeeiro. In: ZAMBOLIM, L. O estado da arte de tecnologias na produção de café. Viçosa: Suprema Gráfica e Editora, 2002. p.369449. 